\title{
Evaluation of nest site preferences of a nest dismantler, the Hair-crested Drongo (Dicrurus hottentottus) in Dongzhai National Nature Reserve of central China
}

\author{
Andrew Cantrell ${ }^{*}$, Lei Lv², Yong Wang ${ }^{1}$, Jianqiang Li ${ }^{2}$ and Zhengwang Zhang ${ }^{2}$
}

\begin{abstract}
Background: The Hair-crested Drongo (Dicrurus hottentottus) exhibits a unique nest-dismantling behavior after the fledging of the young. One hypothesis explaining this behavior is dismantling one's own nest may reduce potential competition for nest sites in the following breeding season because suitable breeding habitat might be limited, and sites are often reused.

Methods: By comparing the habitat features at nest and random locations, we determined the nest habitat preference of the Hair-crested Drongo within Dongzhai National Nature Reserve, Henan, China. We also compared habitat features with nesting success to determine if any trends could be detected.

Results: We found that nest tree height, diameter at breast height, live crown ratio, tree rank, and presence of overstory were significantly higher at nesting locations than random locations; slope, leaf litter cover percentage and depth, presence of understory and midstory, and number of trees per hectare were significantly lower at nest sites than random sites. Drongos preferred to use some tree species, such as Metasequoia glyptostroboides, Castanea mollissima, and Pterocarya stenoptera for nesting. Failed nests were often associated with habitat with higher percentage of leaf litter on the ground.
\end{abstract}

Conclusion: Our data support that selection of nest sites does occur for this species at this site and therefore support the hypothesis that breeding habitat limitation could be one of the driving forces for the development of the nestdismantling behavior in this species.

Keywords: Hair-crested Drongo, Nest dismantling behavior, Nest site selection, China, Dongzhai National Nature Reserve

\section{Background}

The Hair-crested Drongo (Dicrurus hottentottus) is a common bird throughout much of east and southeast Asia. The species is a summer breeder in central and northern China (Zheng 2011); parents usually produce a single brood annually, sometimes with replacement clutches, and are territorial and aggressive to conspecific

\footnotetext{
*Correspondence: andrew.w.cantrell@gmail.com

${ }^{1}$ College of Agricultural, Life and Natural Sciences, Alabama A\&M

University, 4900 Meridian Street North, Normal, AL 35762, USA

Full list of author information is available at the end of the article
}

intruders and other predators (Li et al. 2009). The adults of this species exhibit a unique nest dismantling behavior, in which the adults dismantle the nest following the fledging of the young ( $\mathrm{Li}$ et al. 2009). Some bird species have been known to dismantle their own or other nests for materials to re-nest (Dow 1978; Sedgwick and Knopf 1988; Kershner et al. 2001). Although a few may reuse nesting materials after a failed nest attempt, most drongos dismantle their nests at the end of the breeding period after the young have fledged ( $\mathrm{Li}$ et al. 2009). Li et al. (2009) proposed several hypotheses to explain this behavior; suitable nesting habitat for this species may be 
limited and by removing the landmark (nest), it reduces the probability of use of the same site by competitors during the following breeding season.

To further explore this hypothesis our study examined this species' nest site selection to better understand the competitive nature of nest sites. We examined the nesting site habitat features and compared them to those from randomly selected locations to explore nest habitat characteristics that were preferred by this species. Since nest site selection is often associated with the fitness of a species (Cody 1985; Misenhelter and Rotenberry 2000) we tested the relationship between drongo nesting success to variations in habitat features.

\section{Methods}

\section{Study site}

This study took place in 2011 at Dongzhai National Nature Reserve $\left(31.95^{\circ} \mathrm{N}, 114.25^{\circ} \mathrm{E}\right)$, located in the Dabieshan Mountains of Henan Province of central China. The reserve is located in the transitional area of subtropical and temperate zones. The study was conducted at Baiyun Management Station, which is one of several stations located within the reserve. The forest vegetation is predominantly composed of oaks, Quercus spp., Masson pine (Pinus massoniana), dyetree (Platycarya strobilacea), beautiful sweetgum (Liquidambar formosana), and hupeh rosewood (Dalbergia hupeana) with major shrub species including young oriental oak (Quercus variabilis), glaucous allspice (Lindera glauca), and bamboos (Pleioblastus spp.) (Song and Qu 1996). Dongzhai National Nature Reserve is known for its high avian diversity (over 300 species recorded) and was established initially as a bird reserve (Song and Qu 1996).

\section{Nest searching and monitoring}

Hair-crested Drongos are migratory, arriving at the study site in late April, with the breeding season lasting until early August ( $\mathrm{Li}$ et al. 2009). This species uses three different forest habitat types: broadleaf, coniferous, and mixed broadleaf-coniferous (Gao et al. 2006). This study was conducted during the summer of 2011, beginning in May and ending in August. Nests were found mainly by searching known breeding sites from previous years such as those found by Li et al. (2009) as well as locations suggested by local ornithologists and reserve personnel. After nests were found, most were monitored periodically approximately every 1-3 days. Nest visitation was executed in a systematic fashion to check whether the nests were dismantled during the visiting intervals. For some nests, intensive continuous monitoring was also carried out, but the data were not included in this study. Nest monitoring was also conducted for failed nests to see if parents would reuse nesting material to build a new nest. The results of these methodologies are not given herein as these methodologies only provided this study nest site locations and information on nesting success.

\section{Habitat measurements}

We quantified habitat features using a modified habitat sampling protocol from James and Shugart (1970). For habitat measurements, we selected nest sites that were recently abandoned, failed, successful or currently active; however we gave preference to those that were not currently active to minimize disturbance on nesting behavior. We also did not use nest sites where the nests were completely dismantled (no trace evidence of the nest location) so that recorded habitat variables would be accurate. The variables recorded at each nest site included nest tree species, nest height, nest tree height, nest tree diameter at breast height (DBH), live crown ratio (LCR), tree rank, canopy cover, distance to nest from main tree trunk, length of nest branch, azimuth of nest from tree, slope, aspect, basal area, percent ground cover, and forest stratification. Tree and nest height, LCR, and slope were measured using a hand held clinometer $\left(\right.$ Brunton $\left.^{\circledR}\right)$. All tree DBHs were measured using DBH tape and measured to the $0.01 \mathrm{~cm}$. Each nest tree was given a rank (1-3) based on its position in the canopy. Rank 1 was used for small trees making up the understory and lower midstory; rank 2 corresponded to trees that were overtopped or suppressed by other major canopy trees, in more open habitat a rank of 2 was given if taller trees were present in the surrounding area; rank 3 corresponded to dominant and codominant canopy trees. The distances from nest to tree trunk and nest branch length were estimated by measuring the estimated distance of the nest and branch from the tree trunk on the ground below. Azimuth of nest from tree and aspect were recorded using a compass and then converted into northing and easting using arcsin and arccos.

To record the additional habitat features a plot center was installed directly underneath the nest location. From the plot center four transects were laid in each cardinal direction (N, S, E, and $\mathrm{W}$ ) ending $10 \mathrm{~m}$ from plot center. Canopy cover was recorded at plot center in each cardinal direction (N, S, E, and W) using a hand-held spherical densitometer (Forestry Suppliers Inc.). Basal area was measured at plot center using a ten factor Cruz All angle factor gauge (Forestry Suppliers, Inc.); all "in" trees were identified and measured for DBH. Basal area was used to determine trees per hectare. Ground cover, forest stratification, and litter depth were measured at plot center and at the terminal ends of each transect. Ground cover variables included herbaceous and woody vegetation, leaf litter, bare ground, rock, and water, and were estimated using a $0.5 \mathrm{~m} \times 0.5 \mathrm{~m}$ box sampling plot. Litter 
depth was measured using a ruler and measured to the nearest centimeter. The vertical structure of forest vegetation was estimated by visually assessing the presence or absence of ground cover (0-2 m), understory (2-4 m), midstory ( $>4 \mathrm{~m}$ but lower than overstory height), and overstory (major canopy trees). For each nest location a random location was selected 50-100 m away and at a random compass bearing; both factors were generated using a random seed generator. At each random location the same measurements were taken except for measurements directly linked to nest position (e.g. nest height, distance from nest to tree trunk and branch length). Each random point constituted as the plot center and from this point the closest tree $\geq 5.1 \mathrm{~cm} \mathrm{DBH}$ was established as a pseudo nest tree to determine differences between used and random, but available, nest sites. All measurements were taken by the senior authors to reduce observer bias.

\section{Statistical analysis}

To reduce the dimension among the habitat variables, we conducted a principle component analysis (PCA) with a varimax rotation and Kaiser normalization. Anti-image matrices were used to determine if any variables had low correlations with other variables based on the measures of sampling adequacy (MSA; Hair et al. 2006). Variables with low MSA $(<0.4)$ were removed from the PCA analysis. We used a paired sample $t$ test to determine if there were any differences in habitat variables and PCA components between nesting and random locations. A nest was considered successful if at least one nestling fledged and failed if the nest was predated or abandoned. We used an independent $t$-test to determine if habitat variables and components differed between successful and failed nests. We then used significant components and variables from above analyses as predictors to develop a paired-sample logistic regression model (Hosmer and Lemeshow 1989) to predict used against random locations. To determine if drongos selected specific tree species for nesting, we conducted Chi squared tests by comparing the proportions of the availability of different tree species from random locations with actual nesting locations. All statistical analyses were performed with SPSS v.19 (SPSS 2011). We reported means with standard error (SE), unless otherwise noted, and declared statistical tests significant when $P<0.05$.

\section{Results}

We found a total of 98 nests and selected 50 nests for measuring habitat variables. The 50 nests were mainly selected based on nest activity (see "Habitat measurements" section); however, accessibility and time limitability were also slight factors. We measured all habitat variables at all nests, with the exception of seven nests.
For these seven, we did not record nest branch length and tree to nest length due to obstructing vegetation. The drongos used trees for nesting non-randomly $\left(\chi^{2}=110.3\right.$, $P<0.001$ ) and preferred Chinese water fir (Metasequoia glyptostroboides, $34 \%$ ), Chinese chestnut (Castanea mollissima, $20 \%$ ), Chinese wingnut (Pterocarya stenoptera,14\%), and paulownia (Paulownia fortune, $10 \%$ ) and avoided trees such as the Masson pine and Chinese fir (Cunninghamia lanceolata) (Fig. 1).

The Hair-crested Drongo used trees with average heights of $18.90 \pm 1.03 \mathrm{~m}$ (Table 1). The nests were located on branches $5.85 \pm 1.05 \mathrm{~m}$ in length in the midlevel of trees (average nest height: $8.3 \pm 0.55 \mathrm{~m}$ ), with nests being built $71.53 \pm 2.26 \%$ along these branches (Table 2). The drongos preferred larger trees to build nests. The nesting trees were greater in height $\left(t_{49}=7.73\right.$, $P<0.001)$, DBH $\left(t_{49}=6.49, P<0.001\right)$, vegetation rank $\left(t_{49}=6.3, P<0.001\right)$, and LCR $\left(t_{49}=3.85, P<0.001\right)$ than that of random locations (Table 1$)$. Nesting locations consisted of lesser slope $\left(t_{49}=-4.56, P<0.001\right)$, litter cover $\left(t_{49}=2.69, P=0.010\right)$ and litter depth $\left(t_{49}=2.35\right.$, $P=0.023)$ than at random locations. Random locations also had a higher presence of understory $\left(t_{49}=2.58\right.$, $P=0.013)$, midstory $\left(t_{49}=4.21, P<0.001\right)$, and trees per hectare $\left(t_{49}=-4.6, P<0.001\right)$ than nest locations, but a lesser overstory $\left(t_{49}=4.53, P<0.001\right)$.

The forest composition contributing to the BA within used and random locations consisted of $1.74 \pm 0.67$ (SD) and $1.81 \pm 1.28(\mathrm{SD})$ tree species, respectively. The primary species making up the used areas consisted of Chinese water fir (39.9\%), Chinese wingnut (14.8\%), and Chinese chestnut (12.8\%), and the random areas were dominated by Chinese fir (27.6 \%), Masson pine (24.1\%), and sawtooth oak (Quercus acutissima, 14.6\%).

\section{PCA and logistic regression}

We conducted an initial PCA analysis with all habitat variables and removed bare ground and rock covers and trees per hectare for the final PCA analysis because of their low MSA. The new PCA was able to extract five components (eigenvalue $>1$ ) that accounted for $73.5 \%$ of total habitat variance (Table 3). Component 1 represented a gradient of higher canopy cover, overstory and $\mathrm{BA}$, but low woody vegetation as ground cover. Component 2 was positively correlated to presence and depth of litter, slope, and presence of midstory. Component 3 was positively correlated to presence of woody vegetation and CWD. Component 4 correlated positively with ground cover and negatively with presence of water, while component 5 was correlated positively with understory and canopy cover. Consistent with univariate analysis, component 1 and 2 differed between nest and random locations $\left(t_{98}=2.61, P=0.01\right.$, and $t_{98}=-4.98, P<0.001$, 


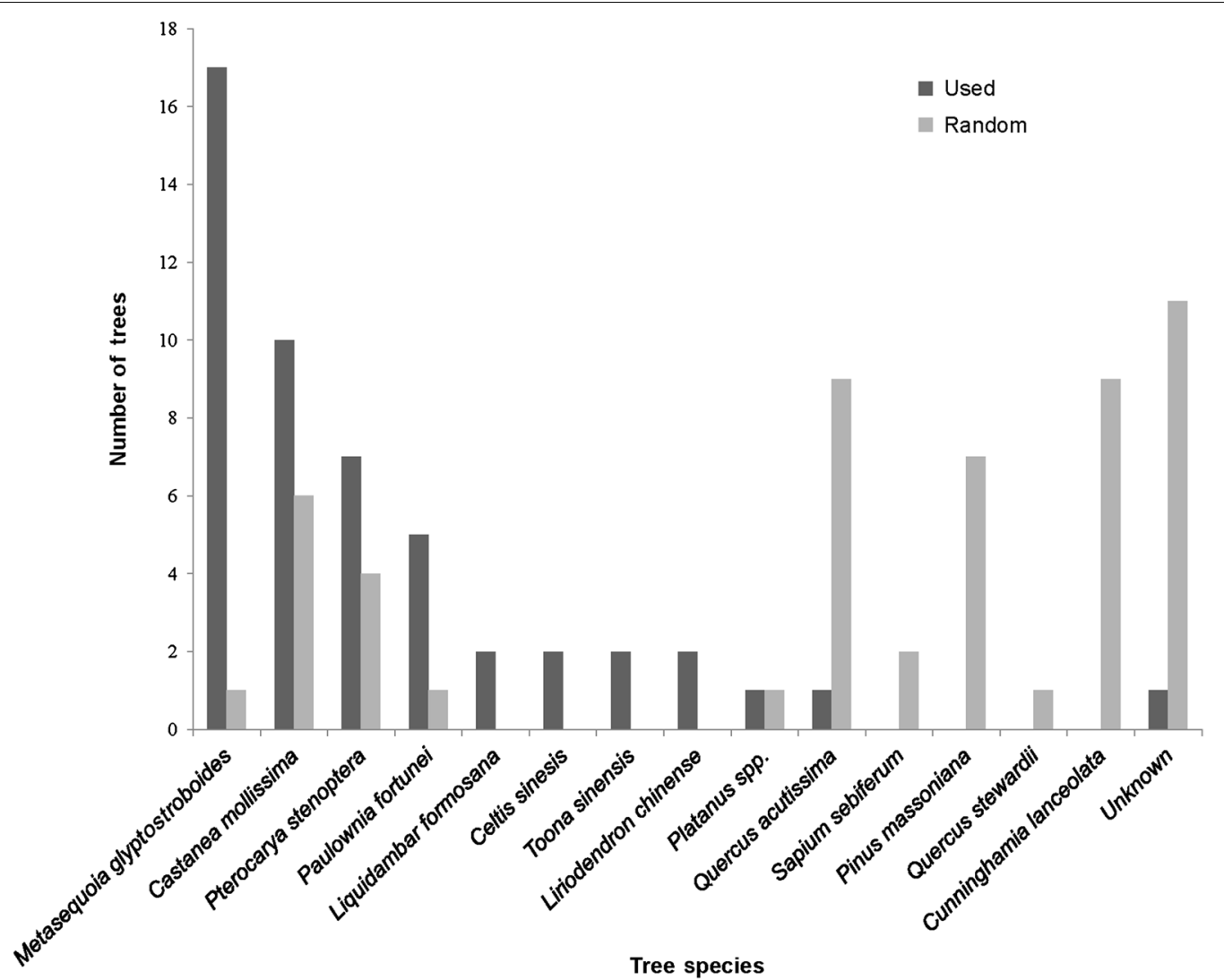

Fig. 1 Comparison of tree species between random locations and those used for nesting by the Dicrurus hottentottus at Dongzhai National Nature Reserve, Henan, China in 2011

respectively), suggesting that drongos preferred locations with minimal slopes, larger trees in the main canopy with less midstory coverage and litter depth (Fig. 2). Paired sample logistic regression supports our findings showing that component 1 and 2 were significant predictors $(B=2.07, P=0.02$; and $B=-1.74, P=0.02$, respectively).

The only variable that was different between failed and successful nests was the amount of litter cover with failed nests $(n=14)$ having a higher percentage of litter in the ground cover than successful nests $(n=35)\left(t_{47}=-2.28\right.$, $P=0.03)$.

\section{Discussion}

Hair-crested Drongos in Dongzhai National Nature Reserve were observed nesting in a diverse array of landscapes such as forests, Chinese water fir plantations, over and near roads and villages, and near agricultural fields. Despite the differences in landscapes, this species showed preference to nest in main canopy trees with larger DBH and LCR. The stands used for nesting typically had fewer, yet larger trees, while having a more open understory and midstory, and less vegetation in these zones. These stands were usually located within areas with minimal slope, in comparison to the steep mountain slopes that sometimes surrounded nesting locations.

Gao et al. (2006) also found that Hair-crested Drongos preferred areas with larger trees and low slope. However, the DBH of nest trees in our study was approximately $7 \mathrm{~cm}$ larger than those reported by Gao et al. (2006). The number of tree species at nesting locations was very similar to that reported by Gao et al. (2006); however, our random locations consisted of almost twice as many as reported in their study. These differences could be attributed to site specific, temporal, or sampling variations.

Our research has also shown that Hair-crested Drongos prefer certain tree species for nesting. Tree species composition and nesting preference were similar to findings of Gao et al. (2006); however, they found beautiful sweetgum to be the major tree for nesting, which is probably due to site specific variation in tree composition. Gao et al. (2006) also suggested this species uses coniferous forests for nesting, but we found that the only coniferous tree used by Hair-crested Drongos for nesting was the Chinese water fir. The other three common coniferous trees at the study site were Masson pine, Chinese 
Table 1 Mean \pm SE of habitat variables for Dicrurus hottentottus at nesting and random locations in Dongzhai National Nature Reserve, Henan, China in 2011

\begin{tabular}{|c|c|c|c|c|}
\hline Variable & Nest site & Random site & $t$ & $P$ \\
\hline Tree height (m) & $18.9 \pm 1.03$ & $9.91 \pm 0.84$ & 7.73 & 0.000 \\
\hline Live crown ratio & $60.58 \pm 2.57$ & $43.71 \pm 2.95$ & 3.85 & 0.000 \\
\hline $\begin{array}{l}\text { Diameter at breast height } \\
(\mathrm{cm})\end{array}$ & $33.45 \pm 2.01$ & $16.36 \pm 1.85$ & 6.49 & 0.000 \\
\hline Tree rank & $2.73 \pm 0.07$ & $1.96 \pm 0.10$ & 6.30 & 0.000 \\
\hline Canopy cover (\%) & $79.89 \pm 2.11$ & $79.16 \pm 3.03$ & 0.23 & 0.819 \\
\hline Slope $\left({ }^{\circ}\right)$ & $15.24 \pm 1.68$ & $27.50 \pm 2.01$ & -4.56 & 0.000 \\
\hline Aspect N & $0.04 \pm 0.10$ & $-0.05 \pm 0.10$ & 0.63 & 0.535 \\
\hline Aspect E & $-0.15 \pm 0.10$ & $-0.03 \pm 0.11$ & -0.79 & 0.432 \\
\hline Azimuth N & $-0.02 \pm 0.10$ & $0.02 \pm 0.10$ & -0.33 & 0.742 \\
\hline Azimuth $\mathrm{E}$ & $0.05 \pm 0.10$ & $-0.04 \pm 0.10$ & 0.63 & 0.535 \\
\hline Herbaceous (\%) & $39.23 \pm 2.38$ & $32.89 \pm 3.04$ & 1.75 & 0.086 \\
\hline Wood (\%) & $13.73 \pm 1.82$ & $14.04 \pm 1.84$ & -0.13 & 0.900 \\
\hline Bare ground (\%) & $6.53 \pm 1.44$ & $6.32 \pm 1.70$ & 0.08 & 0.935 \\
\hline Litter (\%) & $31.78+2.01$ & $40.03 \pm 2.88$ & -2.69 & 0.010 \\
\hline Rock (\%) & $4.1 \pm 1.02$ & $4.69 \pm 1.15$ & -0.44 & 0.662 \\
\hline Coarse woody debris (\%) & $1.96 \pm 0.46$ & $2.32 \pm 0.48$ & -0.54 & 0.593 \\
\hline Water $(\%)$ & $1.64 \pm 0.92$ & $0.02 \pm 0.02$ & 1.76 & 0.085 \\
\hline Litter depth (cm) & $2.64 \pm 0.19$ & $3.22 \pm 0.22$ & -2.35 & 0.023 \\
\hline Ground cover & $0.96 \pm 0.01$ & $0.96 \pm 0.02$ & -0.20 & 0.844 \\
\hline Understory & $0.35 \pm 0.04$ & $0.48 \pm 0.05$ & -2.58 & 0.013 \\
\hline Midstory & $0.4 \pm 0.04$ & $0.65 \pm 0.04$ & -4.21 & 0.000 \\
\hline Overstory & $0.7 \pm 0.04$ & $0.46 \pm 0.05$ & 4.53 & 0.000 \\
\hline Basal area $\left(m^{2} / h a\right)$ & $11.16 \pm 1.13$ & $8.90 \pm 0.87$ & 1.55 & 0.129 \\
\hline Trees per hectare & $29.92 \pm 4.24$ & $79.63 \pm 10.30$ & -4.60 & 0.000 \\
\hline
\end{tabular}

Table 2 Measurements of nest related variables recorded at Dicrurus hottentottus nesting sites at Dongzhai National Nature Reserve, Henan, China in 2011

\begin{tabular}{llr}
\hline Variable & N & Mean $( \pm$ SE) \\
\hline Nest height $(m)$ & 50 & $8.28 \pm 0.55$ \\
Nest to tree ratio & 50 & $47.27 \pm 2.74$ \\
Trunk to nest $(m)$ & 43 & $3.92 \pm 0.42$ \\
Nest branch $(m)$ & 44 & $5.85 \pm 1.05$ \\
Nest to branch ratio & 43 & $71.53 \pm 2.26$ \\
\hline
\end{tabular}

fir, and Chinese arborvitae (Platycladus orientalis). Our findings indicate that in areas where these other coniferous species were present, and usually dominant as found by our random surveys, Hair-crested Drongos avoided them and tended to nest in hardwood trees or Chinese water firs. This suggests that Drongos are even more selective when it comes to nesting among coniferous species than in more hardwood dominated areas. Though
Table 3 Principal component analysis components (PC) for habitat variables present at real and random nest sites for Dicrurus hottentottus

\begin{tabular}{lrrrrr}
\hline Variable & PC1 & \multicolumn{1}{c}{ PC2 } & \multicolumn{1}{c}{ PC3 } & PC4 & PC5 \\
\hline Basal area & 0.87 & 0.01 & 0.10 & 0.01 & 0.01 \\
Overstory & 0.81 & -0.11 & -0.14 & 0.24 & 0.05 \\
Slope & -0.16 & 0.79 & 0.15 & 0.07 & 0.12 \\
Litter depth & 0.07 & 0.74 & 0.01 & 0.40 & -0.07 \\
Midstory & 0.06 & 0.65 & 0.15 & -0.05 & 0.37 \\
Litter & 0.46 & 0.60 & 0.32 & -0.13 & 0.25 \\
Herb & 0.05 & -0.25 & -0.81 & 0.20 & -0.30 \\
CWD & 0.06 & 0.20 & 0.79 & 0.14 & -0.25 \\
Wood & -0.55 & -0.24 & 0.56 & 0.37 & 0.16 \\
Ground cover & -0.03 & 0.10 & -0.11 & 0.88 & -0.01 \\
Water & -0.17 & 0.09 & -0.15 & -0.70 & -0.16 \\
Understory & -0.04 & 0.18 & 0.02 & 0.16 & 0.80 \\
Canopy cover & 0.58 & 0.20 & -0.03 & -0.01 & 0.66 \\
\hline
\end{tabular}

our research did not look at the overall composition of the landscape to determine total availability, our findings did provide some evidence on habitat limitability. For example, the two major nesting trees, the Chinese water fir and Chinese chestnut, were typically found as monocultures with higher density of these being detected when the respected tree was used for nesting. Both species were found at low density, $3.5 \%$ for both species, during our random surveys. Chinese water firs were typical of smaller monoculture forest plantations, while Chinese chestnuts were found in more open areas, such as those near agricultural lands. Xu et al. (2007), reported that mixed conifer-broadleaf forests, mainly dominated by oaks, Masson pine, and Chinese fir, mature Masson pine dominated plantations, and mature Chinese fir dominated plantations comprised up to 50.0, 6.0, and $16.1 \%$ of the reserve, respectively. The finding of Xu et al. (2007) that the plantations were dominated by two species of conifers $(72.1 \%)$ that we find to be avoided by Haircrested Drongos provides evidence of habitat limitability.

The only habitat variable that was different between failed and successful nests was litter cover. Nesting success probability increased within areas with lower ground litter cover. Litter cover was also a variable found to be different between nest and random locations; Haircrested Drongos tended to nest in areas with less litter cover. Forest litter is mainly composed of dead plant materials, such as leaves, bark, needles, and twigs that have fallen to the ground. The amount of litter cover on the forest floor could be affected by various variables including season, plant species, climate, soil fertility, elevation, and decomposition rate (Spain 1984; Lonsdale 1988). The most extreme variability of litter fall is seen as 


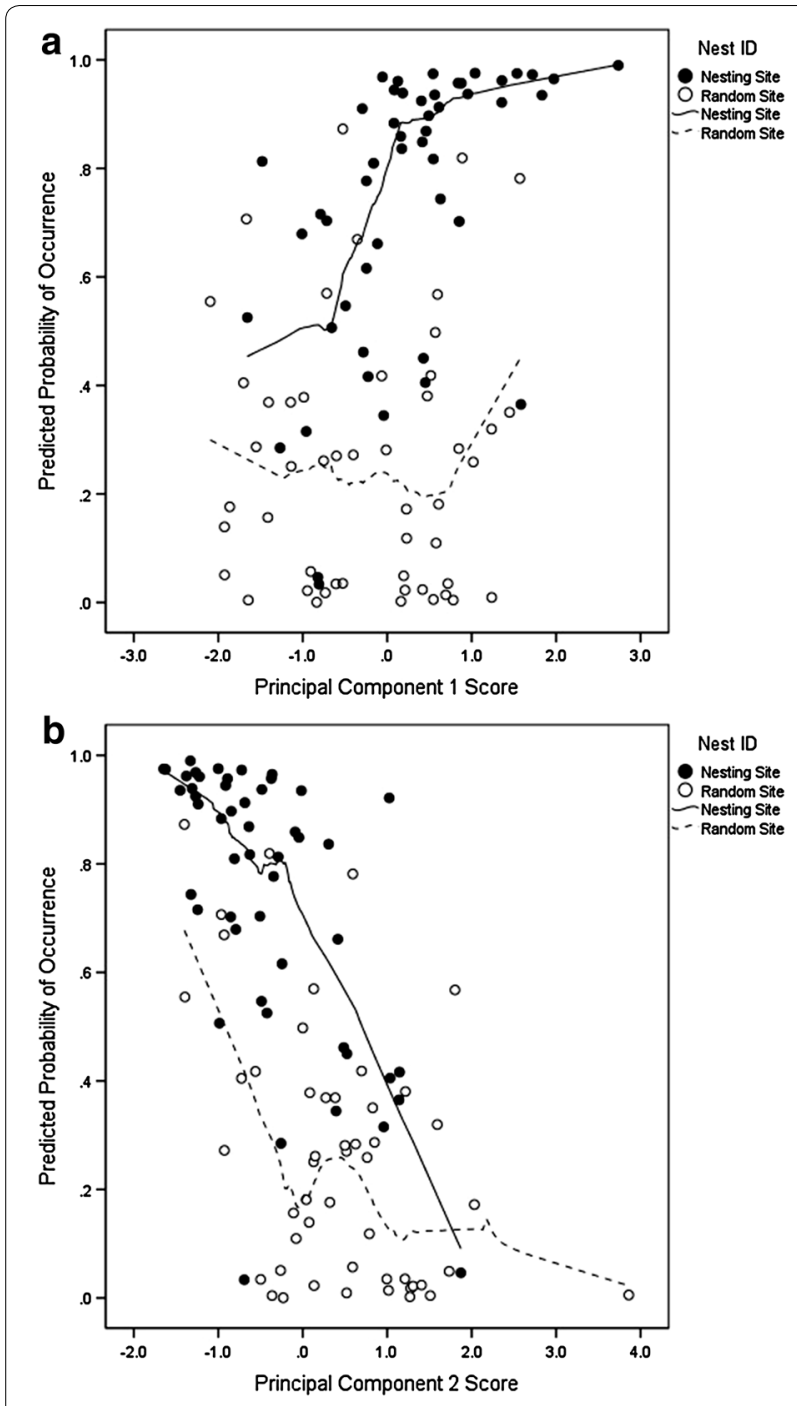

Fig. 2 Predicted probability of Dicrurus hottentottus nesting occurrence to actual nest site habitat variables $(\mathbf{a})$, and predicted probability of nesting occurrence to habitat variables measured at random points (b) at Dongzhai National Nature Reserve, Henan, China in 2011

a function of seasonality; each individual species of plant show different temporal variation in losses of certain parts of its body (Lonsdale 1988). Although other studies suggested that litter layers can directly provide important habitat for some bird species for food resources, nest locations, and cover (Holmes and Robinson 1988; Van Wilgenburg et al. 2001), we had difficulties directly linking the litter cover variation with the benefits the drongos might receive. However, the consistency between the preference of nest locations with fewer and larger trees, less abundant mid- and understory levels, and the feature of successful nests with less ground litter cover led us to speculate that litter cover was a surrogate variable that might be related to the particular habitat features such as food resources (e.g. leaf litter dwelling and foraging insects) and predation risk (e.g. snakes, etc.) affecting the potential breeding success of the Hair-crested Drongos. However, we do recognize that without further testing this could be a case of statistical versus biological significance.

The preference of certain nesting sites by drongos, as found in this study, coupled with habitat limitability provides some supporting evidence of the nest-site competition hypothesis of the nest-dismantling behavior given by $\mathrm{Li}$ et al. (2009). Dongzhai National Nature Reserve and the surrounding rural areas contain many small villages and towns, and much of the surrounding areas include agricultural lands. The continuing human influences upon the landscape, especially in areas surrounding the reserve, could alter and limit the habitat resources for this species by reducing habitat availability. Reducing habitat availability could influence intra and inter species competition for nest sites on both local and landscape scales. How such changes may influence nest-site selection, breeding success, and nest dismantling behavior are unknown but could warrant future investigations. On a local scale, further investigation is warranted to see if any spatial dynamics of nest sites (e.g. distance to closest neighbor), and forest composition, influences not only the nest site selection process but also the nest-dismantling behavior (e.g. would dismantling rate increase or decrease with distance to closest neighbor or within certain habitat types).

\section{Authors' contributions \\ AC was responsible for all aspects of the research in and out of the field, including the planning, conducting, analyzing and writing of manuscript. LL assisted in planning, field logistics, nest location and determining of nesting status. YW assisted in the planning and coordinating with international col- laborators, and also assisted with statistical analyses. ZZ was responsible for overseeing all research activities and completion of project. JL assisted in all logistics in and out of the field. All authors assisted in manuscript review and editing. All authors read and approved the final manuscript.}

\section{Author details}

${ }^{1}$ College of Agricultural, Life and Natural Sciences, Alabama A\&M University, 4900 Meridian Street North, Normal, AL 35762, USA. ${ }^{2}$ School of Life Sciences, Beijing Normal University, Beijing 100875, China.

\section{Acknowledgements}

We appreciate the support by Dongzhai National Nature Reserve for conducting this study. Funding and support was provided by National Science Foundation East Asia Pacific Summer Institute (EAPSI), Chinese Ministry of Science and Technology, and China Science and Technology Exchange Center. Further funding and support was provided by Alabama A\&M University and Beijing Normal University. We want to express our gratitude to Antillo Biancucci, Matthew Lerow, Peng Zhang, and Langyu Gu for their assistance in and out of the field.

\section{Competing interests}

The authors declare that they have no competing interests.

Received: 29 September 2015 Accepted: 11 April 2016

Published online: 04 May 2016 


\section{References}

Cody ML. Habitat Selection in Birds. New York: Academic Press; 1985.

Dow DD. Breeding biology and development of the young of Manorina melanocephala, a communally breeding Honeyeater. Emu. 1978;78:207-22.

Gao ZJ, Du ZY, Wang XS, Huang H, Wang K, Yang CB. The nest-site selection of Hair-crested Drongo Dicrurus hottentottus. Chin J Zool. 2006;41:69-73.

Hair JF, Black B, Babin B, Anderson RE, Tatham RL. Multivariate Data Analysis. 6th ed. Upper Saddle River: Prentice Hall; 2006.

Holmes RT, Robinson SK. Spatial patterns, foraging tactics, and diets of ground-foraging birds in a northern hardwoods forest. Wilson Bull. 1988:100:377-94.

Hosmer DW, Lemeshow SL. Applied Logistic Regression. 2nd ed. New York: Wiley; 1989

James FC, Shugart HH Jr. A quantitative method of habitat description. Audubon Field Notes. 1970;24:727-36.

Kershner EL, Bollinger EK, Helton MN. Nest-site selection and renesting in Bluegray Gnatcatchers (Polioptila caerulea). Am Midl Nat. 2001;146:404-13.

Li J, Lin S, Wang Y, Zhang Z. Nest-dismantling behavior of the Hair-crested Drongo in central China: an adaptive behavior for increasing fitness? Condor. 2009;111:197-201.
Lonsdale WM. Predicting the amount of litter fall in the forests of the world. Ann Bot. 1988;61:319-24.

Misenhelter MD, Rotenberry JT. Choices and consequences of habitat occupancy and nest site selection in sage sparrows. Ecology. 2000;81:2892-901.

Sedgwick J, Knopf FL. A high incidence of Brown-headed cowbird parasitism of Willow Flycatchers. Condor. 1988;90:253-6.

Song CS, Qu WY. Scientific investigation on Dongzhai National Nature Reserve. Beijing: China Forestry Publishing House; 1996.

Spain AV. Literfall and the standing crop of litter in three tropical Australian rainforests. J Ecol. 1984;72:947-61.

Van Wilgenburg SL, Mazerolle DF, Hobson KA. Patterns of arthropod abundance, vegetation, and microclimate at boreal forest edge and interior in two landscapes: implications for forest birds. Ecoscience. 2001;8:454-61.

Xu JL, Zhang ZW, Zheng GM, Zhang XH, Sun WH, McGowan P. Home range and habitat use of Reeve's Pheasant Syrmaticus reevesii in the protected areas created from forest farms in the Dabie Mountains, central China. Bird Conserv Int. 2007;17:319-30.

Zheng GM. A checklist of the classification and distribution of the birds of China. Beijing: Science Press; 2011

\section{Submit your next manuscript to BioMed Central and we will help you at every step:}

- We accept pre-submission inquiries

- Our selector tool helps you to find the most relevant journal

- We provide round the clock customer support

- Convenient online submission

- Thorough peer review

- Inclusion in PubMed and all major indexing services

- Maximum visibility for your research

Submit your manuscript at www.biomedcentral.com/submit
() Biomed Central 